\title{
Assessment of potential local and regional induced economic impact of an energy policy change in rural Northwestern Ontario
}

\author{
Jason E. E. Dampier ${ }^{1 *}$, Chander Shahi ${ }^{1}$, R. Harvey Lemelin ${ }^{2}$ and Nancy Luckai ${ }^{1}$
}

\begin{abstract}
Background: In 2002, the province of Ontario introduced plans to ban coal in thermoelectric power production. Rural communities with a high proportion of power plant jobs (such as Atikokan, Ontario, Canada) grappled with three potential outcomes of the planned changes. These include the following: (i) the coal ban is overturned and power plants continue to burn non-renewable coal, (ii) the coal ban takes effect and power plants are closed, and (iii) the coal ban takes effect but power plants continue operating with alternative renewable fuel sources such as woody biomass. Considering there is a lack of readily available economic assessment tools for Ontario communities, the objective of this study is to model how direct changes in employment at the power plant (and indirect employment at associated local industries) impact the spending patterns of households associated with the power plant.
\end{abstract}

Methods: To address the objective, an induced economic impact assessment model was developed by integrating quantitative publically available data sources with community-level qualitative data sources incorporating them into an input-output approach. Baseline values were established, representing induced community expenditure under the coal scenario. Values were then adjusted to represent induced community expenditure under shutdown and biomass scenarios.

Results: The model suggests that the continuation of coal would allow for $\$ 82.7 \mathrm{M}$ in household spending, the shutdown reduces overall household spending to $\$ 72.1 \mathrm{M}$ which represents a decrease of $12.8 \%$, and the conversion to woody biomass as the sole fuel for the power plant increases household spending relative to the coal by $\$ 1.2 \mathrm{M}$ or $1.4 \%$. The results also indicate that the induced economic impact would be realized throughout the region, beyond Atikokan.

Conclusions: These results suggest that biomass conversion could produce a net positive-induced economic effect as household spending increases, provided local biomass fuel supply is available. Since a conversion to biomass from coal at this scale is a North American first, other jurisdictions may gain insight from this study as they consider reducing their environmental footprint. Furthermore, the induced economic impact model method which is presented here could easily be adapted and used for other Ontario communities which lack access to established input-output models.

Keywords: Atikokan Generating Station, Bioenergy, Economic impact, Electricity generation, Energy security, Social impacts, Wood pellets

\footnotetext{
* Correspondence: jason.dampier@lakeheadu.ca

${ }^{1}$ Faculty of Natural Resources Management, Lakehead University, 955 Oliver

Road, Thunder Bay, Ontario P7B 5E1, Canada

Full list of author information is available at the end of the article
} 


\section{Background}

Canadian communities are dependent on a resourcebased single industry from an important part of a culturally distinctive Canadian landscape [1]. The industry in these communities is sometimes viewed as "always on the verge of closing, but never actually closing" [2]. Studies investigating community dynamics suggest that singleindustry communities that acknowledge and embrace their real or perceived vulnerabilities tend to be more successful and resilient [3-7]. Furthermore, proximity to other communities can have both positive and negative economic impacts on the community under investigation. On the one hand, when a small community undergoes a contracting economy, commuting distance to a larger center with a larger job market can increase community resilience since families can still remain in the community. On the other hand, close proximity to other larger centers can entice community members to shop outside of their own community (known as out-shopping), reducing community resilience as the positive local economic impacts are lost [8-12]. Out-shopping can be framed in terms of a local trade area, which can be simply defined as "a geographic area from which a community generates the majority of its customers" [13].

Although population centers, (with a population of at least 1000 and a density of 400 or more people per square kilometer) [14] and rural areas, are often perceived as being distinct from one another [15-18], provincially elected decision-makers sometimes make provincial-wide policy without fully assessing their decisions' impact on rural communities or rural areas [19-22]. Indeed, these policies are sometimes criticized as being more closely aligned with interests in densely populated urban population centers than with those of sparsely populated rural areas. With $14 \%$ of Ontario's approximately $13 \mathrm{M}$ residents living in rural areas [23], the economic impact of provincial policy needs to be evaluated through the lens of people living and working in rural areas and through the lens of people living in population centers in remote rural areas. Furthermore, these rural areas are important and support the development of Canada with industries such as manufacturing continuing to play an important role [24]. From 1914 to 2006, Bollman [25] outlines three key drivers which have sustained rural Canadian economies, and they include (i) advances in labor saving technology which keep production costs lower, (ii) reductions in the cost of doing business in rural areas with transportation and telecommunications becoming more affordable over the past few decades, and (iii) shifts in demographics which include growth in population of the Aboriginal community (a potential labor source) and young adults and early retirees being attracted to rural areas.

The economy of Atikokan, a small rural community in Northwestern Ontario, has been centered on resource- based industry with a small number of primary employment sectors (forestry, lumber, pulp and paper, and mining) historically employing a relatively large proportion of the workforce [26]. Even prior to the Atikokan power plant's construction in the 1980s, the community's economy has been reliant upon resource-based industry such as forestry, forest products, and mining [27]. However, the forest sector faced an economic downturn during the 2000s. The Canadian Chamber of Commerce reported that between 2004 and 2009, the market value of Canada's forest products fell by $47 \%$ [28]. This is corroborated with other sources. Since 2008, and even prior to the economic contraction (2001-2006), the region's overall gross domestic product (GDP) declined by $6.7 \%$ [26, 29].

It was during the early period of economic contraction, in 2002, that the province of Ontario first established the framework and policy banning coal in thermoelectric power production $[30,31]$ in order to address health and environmental concerns of people living in population centers [32]. During the 9-year period from 2003 to 2011, the use of coal in power generation has been on a steady decline from over $20 \%$ of Ontario's electricity being produced by coal in 2003 to less than $3 \%$ in 2011 [33]. As more was learnt about the coal ban, people living in the rural communities with a high proportion of power plant jobs grappled with three potential outcomes of the coal ban policy. These include the following: (i) the coal ban is overturned and power plants continue, business as usual, to burn coal-coal scenario, (ii) the coal ban takes effect and power plants are decommissioned and closed-shutdown scenario, and (iii) the coal ban takes effect and power plants continue operating with alternative renewable fuel sources such as woody biomass (produced in a local wood pellet plant)_biomass scenario [27].

The coal ban policy directly impacted the four power generating stations in Ontario (i.e., Lambton, Nanticoke, Thunder Bay, and Atikokan) with the power plant near the Northwestern Ontario Town of Atikokan (48 45' $0^{\prime \prime} \mathrm{N}, 91^{\circ} 37^{\prime} 0^{\prime \prime} \mathrm{W}$; $393 \mathrm{~m}$ above sea level) being the only one located in a remote rural area. The community is considered remote and rural due to its nearest neighboring centers being Thunder Bay (population approximately 110,000) which is $210 \mathrm{~km}$ to the east, Fort Frances (population approximately 8000) which is $150 \mathrm{~km}$ to the west, and Dryden (population approximately 7500) which is $210 \mathrm{~km}$ to the north (Fig. 1). The community is not serviced by passenger flights or rail and has regional bus service three times a week to Fort Frances and Thunder Bay.

Ultimately, Atikokan Generating Station (AGS) was saved when the decision was made to convert it to $100 \%$ woody biomass [34]. It was anticipated that the conversion would also increase regional demand for woody biomass [35] with woody feedstock primarily coming from public 


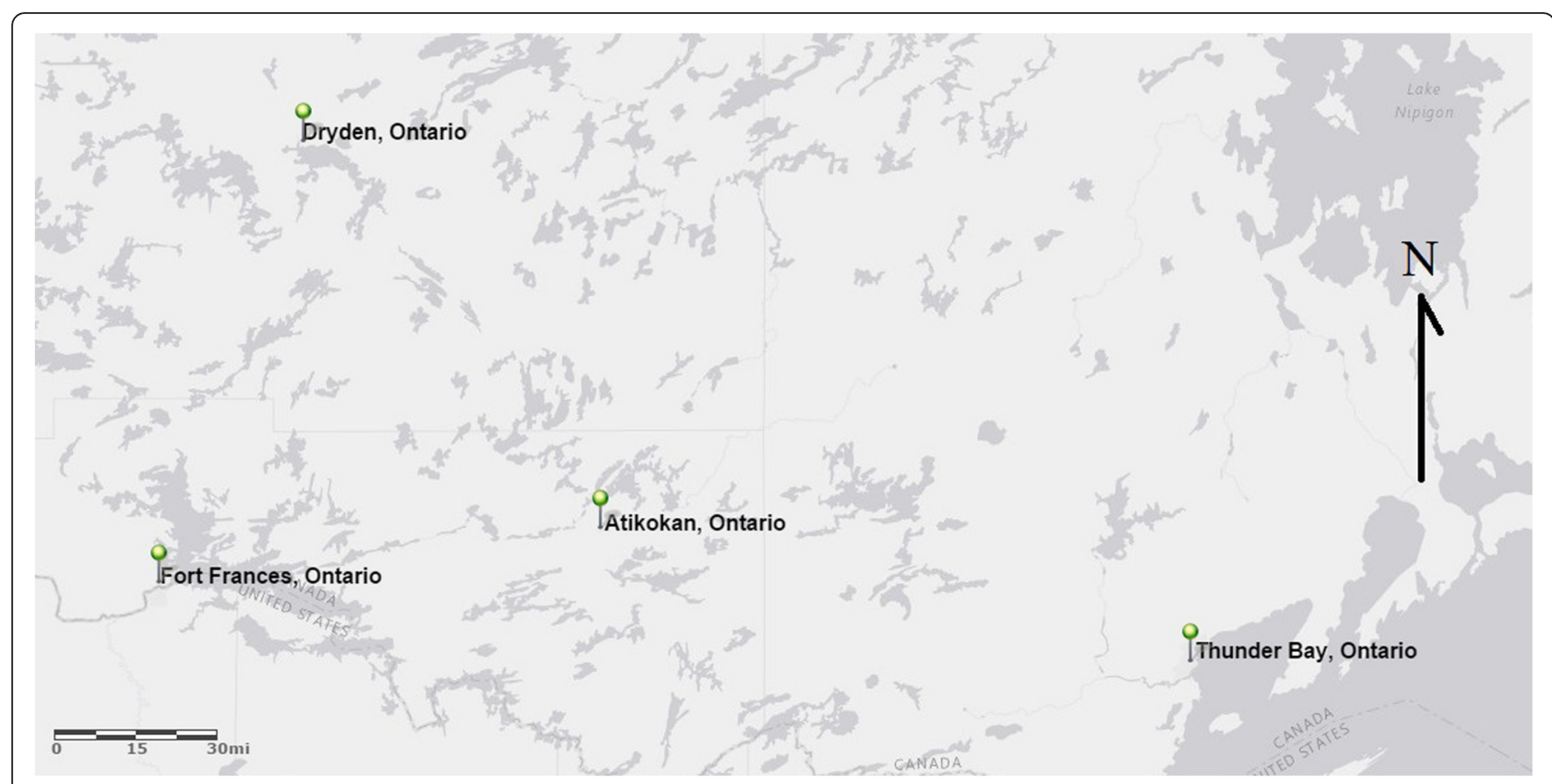

Fig. 1 Location of Atikokan and major regional communities in Northwestern Ontario, Canada

forests in Ontario, managed under the Crown Forest Sustainability Act [36]. An earlier study operated on the initial assumption that the AGS would require 200,000 oven-dried tonnes (ODT) of biomass wood pellets [37]. However, in light of demand and production costs, the power supply agreement in its final form requires a total of 90,000 ODT of biomass wood pellets per year for full conversion, with Atikokan Renewable Fuels (located in Atikokan) supplying 45,000 ODT of biomass wood pellets and Resolute Forest Products Canada (located in Thunder Bay) providing the other 45,000 ODT [38-41]. These two pellet producing firms provided their own investment and capital when getting their operations established. This demand for wood pellets should be easily achieved. Alam and others demonstrated that there is adequate forest harvest residue and underutilized wood biomass feedstock available in Northwestern Ontario to meet the demand [42]. Furthermore, additional woody biomass stock would also likely come from sawmill residues and waste, further reducing the pressure on forest resources. With the coal ban policy being enacted, the province of Ontario has become the first jurisdiction in North America banning coal in electricity production which presents a unique research opportunity [30, 31, 43].

The power plant located near Atikokan had a workforce of about 90 people with many of these individuals contributing to the community's social fabric [39]. In addition to power plant jobs in Atikokan, there were approximately 200 retail and consumer service sector businesses estimated in 2010 [44], which generally rely on household expenditures and are vulnerable to changes in spending patterns (induced effects) [26]. Furthermore, the community's population (population $=2730$, population density $=183.4$ people $/ \mathrm{km}^{2}$ ) [45] and isolation may have contributed to its potential vulnerability. An earlier stage in this project presents qualitatively how Atikokan's community members recognize that the outcome of the coal ban policy would have direct, indirect, and induced economic impacts on their community [27].

Direct economic impacts are created by the sector of interest, indirect economic impacts are experienced by the sectors that provide production inputs to the sector of interest, and induced impacts result in changes in household expenditures from people employed directly and indirectly by the sector of interest [46]. Direct impacts in this study are the positive or negative direct changes in workforce participation at the power plant in Atikokan. Indirect impacts are those changes in local workforce participation from sectors providing production inputs and services to the power plant. Finally, induced impacts (which is the response variable in this study) are the local household expenditures for households with employment at the power plant and the household expenditures for households with employment from sectors that provide production inputs and services to the power plant.

\section{Review}

The literature indicates that a dearth of peer-reviewed research exists investigating socio-economic impacts of biomass burning in thermoelectric generating stations for the Ontario (and Canadian) context [33]. This is, 
however, not the case in all jurisdictions. Resources and policies in Northern Europe and the USA have allowed the expansion of biomass utilization and research for power generation [47]. For example, studies from the southern USA examine how changes in woody biomass production and utilization can generate direct, indirect, and induced economic impacts such as job growth in forestry and forest product manufacturing [48, 49]. Findings also suggest that as domestic and international demand for pellets increase (necessitating larger pellet plants), growth in regional economic activity could be expected in the South $[48,50]$.

Assessment of direct, indirect, and induced economic effects is typically conducted utilizing input-output analysis (IOA). IOA was pioneered by Nobel Laureate Wassily Leontief [51-54] and his work is the basis for present-day national accounts, such as GDP calculations. IOA is commonly used to analyze economic relationships between industries in an economy [50]. For example, how would changes in the wood pellet industry economically impact forestry operations, or how would changes the wood pellet industry economically impact its workers' household expenditure within a local or regional economy?

A challenge facing researchers engaged in communitylevel economic analysis is the lack of accessible IOA data and models at the community level. Modeling software such as IMpact analysis for PLANning (IMPLAN) utilizes IOA along with region-specific social accounting matrices and multipliers [55]. However, presently, IMPLAN does not have community-level social accounting matrices and multipliers for Canadian communities (only data at national and province levels); contrast with this IMPLAN data availability at for the USA which has data at the county and zip code levels. When these data in IMPLAN (or other similar models) become available for sparsely populated regions in Canada, it could become an effective tool in assessing direct, indirect, and induced economic impacts at the local and regional level. Secondary public input-output data from sources such as Statistics Canada could be another data option in assessing local economic impacts. However, at the community level, Statistics Canada suppresses input-output data (which is used for national account such as GDP) at the local level, thusly necessitating an approach which does not rely on such data, hence our approach to integrate quantitative and qualitative data sources.

Our study seeks to fill a methodological gap by developing an improvised method that can be used to characterize economic impacts in Ontario communities such as Atikokan where available IMPLAN data is too course grain, and Statistics Canada input-output data is suppressed. Furthermore, due to the lack of peer-reviewed Canadian studies which investigate community-level economic impacts of biomass conversion on coal power plants, this study will fill this knowledge gap as well. The objective of this study is to develop a model that estimates direct, indirect, and induced economic impact with respect to employment changes at the power plant (and its associated industries) based on household expenditure.

\section{Methods}

Due to the unavailability of input-output data from which to build a model for Atikokan (or any small Ontario community for that matter), other reliable data sources from Statistics Canada were identified and pro-rated in order to develop an induced economic impact assessment model employing an improvised input-output approach. The developed method follows a commitment to pragmatism and to "what works" [56-59]. Due to the flexibility required, pragmatism allows for a "fusion of approaches" and is "expedient" [58].

Specifically, provincial-level household expenditure data, local-level household income data, regional shopping behavior data, and local-level expert knowledge and opinion were used to develop the economic impact assessment model. Household data rather than individual job data were used in calculating induced economic impacts because individual jobs data are not readily available. The Ontario-level 2010 Survey of Household Spending (SHS) was accessed through the Statistics Canada website [60]. These data provide total household expenditure partitioned into five quintiles based on before-tax household income. These values were then used uniformly for the three power plant scenarios.

The 2010 Statistics Canada National Household Survey (NHS) data for Atikokan were collected from the Statistics Canada website [61] in order to estimate Atikokan household counts in each income quintile. These values become the model's initial parameter establishing the baseline numbers from which the household adjustments would be made.

Since NHS data are not organized into income quintiles (but in income classes), this presents a minor challenge of synchronizing the SHS data with NHS data. This challenge was overcome by pooling and proportioning the NHS income class counts into quintiles in order to synchronize the two data sets. The combining of the two secondary datasets was conducted in MS Excel as spreadsheet model. These estimated expenditures per household (SHS) and household counts (NHS) were then multiplied in order to estimate total expenditure for each quintile and summed to provide the overall expenditure. These calculated expenditure values were treated as baseline and represent the coalburning scenario, as in 2010, coal was the sole fuel at the power plant. The model assumes that employing higher-level provincial household expenditure data at 
the community level is valid. This approach may introduce a source of error since it is unlikely that provincial-level spending is perfectly patterned at the community level. However, these potential errors would have been applied equally across the three scenarios and therefore cancel each other out for scenario comparative purposes. Additionally, the model assumes that the primary mechanism in induced economic effects and household expenditure is directly pegged to household income. For example, as household incomes increase, so does household expenditure.

Household expenditure for each quintile can be described with the following equation:

$$
C=A+M D
$$

where

$C=$ aggregate household expenditure

$A=$ autonomous expenditure, which is the fixed level of household expenditure regardless of household income levels (e.g., monthly food and housing expenditures)

$M=$ marginal propensity to consume, which is the ratio of expenditure a household is willing to spend of its real disposable income

$D=$ real disposable income, which is what money is available after deductions of taxes from the total income

For each quintile, the SHS captures household autonomous expenditure, marginal propensity to consume, and real disposable income. In addition, the SHS collects the annual income of household members. The SHS expenditure values are expressed in dollar values and presented here as a total basket of goods purchased on an annual basis.

Summing each quintile household expenditure value is expressed as follows:

$$
C_{\text {tot }}=\sum_{n=1}^{5} C_{n}
$$

where

$C_{\text {tot }}=$ the total household expenditure

$C_{n}=$ total household expenditure for each quintile

In order to estimate total expenditures by each income quintile (and subsequently overall expenditure) for the shutdown and biomass scenarios, adjustments in the baseline household counts were made by applying household income assumptions obtained through qualitative community-level data [27]. Interviews from community members $(n=25)$, consultant reports $(n=16)$, and local newspaper articles $(n=46)$ were collected during the summer of 2013 and analyzed. Sampling and participant selection employed widely accepted qualitative sampling approaches using a purposeful sampling method. Only participants and qualitative data possessing specific criteria were considered. Selected participants both represent and symbolize the established criteria [62, 63] which included having (a) a direct connection to business, governance, entrepreneurship, or industry activities within Atikokan; (b) a good historical knowledge of Atikokan; and (c) a knowledge of the new industrial processes including wood pellet production and supply value chain.

Potential participants from the town of Atikokan (who met the criteria from the purposeful sampling method) were invited to participate in a semi-structured interview $[64,65]$. The collection of interviews (as well as sources such as newspaper articles, consultant reports, and archival data) continued until data saturation was achieved; which is when no new analytical insights can be gained with including additional qualitative data $[63,66,67]$. Qualitative data was analyzed using NVivo 10 software [68] and underwent a qualitative content analysis [69-72]. The qualitative community-level data provides insight into the shutdown and biomass scenarios and their potential direct and indirect economic impacts on household incomes and induced household expenditures.

After the induced economic impacts of household expenditures for each of the three scenarios were determined, the local and regional impacts were estimated by applying published spatial spending habit multipliers for Atikokan's residents [73]. Multipliers are pro-rated factors of proportionality, which indicate how factors such as household income can affect other segments of the economy, such as the retail sector. Local trade area estimates suggest that $50 \%$ of Atikokan households purchased goods and services locally, $10 \%$ in Fort Frances, $20 \%$ in Thunder Bay, 5 \% in Dryden, $10 \%$ in the USA, and $5 \%$ in outside of these communities [73]. Finally, case studies from communities elsewhere were sought in order to provide additional insight into the results presented here. Furthermore, the coal scenario's induced household expenditure was evaluated against the shutdown and biomass scenarios in light of expect inflation rates. Typical annual Canadian inflation (consumer price index) rates are between 1 and $2 \%$. If shutdown and biomass results fell within this range, the results could be interpreted as within a "normal" system parameter for a Canadian community's economy.

\section{Results and discussion}

The model indicates that the town of Atikokan would experience induced economic impacts as households were gained or lost in the income quintiles under the three scenarios. With the coal scenario as the baseline, a general decrease in household counts and an overall decrease in induced household expenditure occur under the shutdown scenario. A general increase in household counts, and an overall increase in induced household expenditure occurs under the biomass scenario. 
Table 1 presents total household expenditure and household counts for each quintile, as well as the total household expenditure for each quintile. The summed quintiles for the coal scenario indicate that there were 1245 households in Atikokan in 2010, with a total household expenditure of \$82.7M. Due to regional shopping patterns, not all of the $\$ 82.7 \mathrm{M}$ would be available to Atikokan's local trade area with only an estimated $\$ 41.4 \mathrm{M}$ staying locally (Table 2). Other neighboring communities within the region such as Fort Frances $(\$ 8.3 \mathrm{M})$, Thunder Bay $(\$ 16.5)$, and Dryden $(\$ 4.1 \mathrm{M})$ are impacted by Atikokan household expenditures. These values for the coal scenario serve as a baseline (or basis for comparison) for the other two alternative scenarios.

For the shutdown scenario, the contracting economy reduces overall households to 1115 and household expenditures down to $\$ 72.1 \mathrm{M}$ (Table 1). The adjustments in household counts are made based on the results of the qualitative data analysis. These data suggest that the power plant would lose all (or nearly all) of its jobs. "Ninety good-paying jobs" at the power plant was a phrase that was repeatedly mentioned. Data also suggest that employees at the power plant average an annual salary of $\$ 100,000$ per year. Additionally, one source suggests that up to 80 indirect jobs could be lost in a shutdown scenario [74], although we take a conservative approach and reduce indirect jobs by a total of 40 , rather than by 80 . The loss of the full 80 indirect jobs is possible; however, since the impacts are being modeling shortly after the shutdown, it is assumed that only 40 indirect jobs would be lost immediately, with the other 40 on a longer time horizon. Furthermore, it is assumed that the lowest quintile would not be immediately affected by the shutdown scenario, since technical and professional jobs directly and indirectly associated with AGS typically compensate at a higher level and hence not adjusted.
Employing these assumptions, baseline coal scenario's household counts are adjusted in order to simulate a power plant shutdown. Of the 40 households affected indirectly, 30 were reduced in the second quintile and 10 in the third quintile (Table 1). It is assumed that indirect jobs represent the workforce employed by establishments which provide goods and services directly to AGS and carry compensation levels typical of the second and third quintiles. The third quintile is reduced by an additional 10 households to account for households relying directly on the power plant, bringing the third quintile to 204 from the baseline of 224 households. Other reductions from the loss of the households relying directly on power plant jobs include 65 from the fourth quintile (193 households in coal to 128 in shutdown) and 15 from the highest quintile (180 households in coal to 165 in shutdown). Therefore, the loss of 90 households directly relying on the power plant occurred across the three upper quintiles.

As Table 2 indicates, the Atikokan local trade area would experience the greatest impact of the shutdown scenario. Relative to the coal scenario, this contraction from $\$ 41.4 \mathrm{M}$ to $\$ 36.1 \mathrm{M}$, which represents a decrease of $12.8 \%$ in the household expenditure, is a substantial amount for the isolated rural community of less than 3000 people. Other neighboring communities would also experience an economic impact from the shutdown. Fort Frances and Thunder Bay stand to lose $\$ 3.2 \mathrm{M}$ ( $\$ 1.1 \mathrm{M}$ in Fort Frances and $\$ 2.1 \mathrm{M}$ in Thunder Bay) in the power plant shutdown scenario. The community of Dryden, as well as cross-boarder shopping into the USA, would also be affected by reductions in household spending (Table 2).

When Atikokan community leaders reflected on potential changes at the power plant, they viewed the shutdown as catastrophic for the local economy and the renewable biomass conversion as a boon [27]. While the

Table 1 Estimated household counts and expenditure per quintile

\begin{tabular}{|c|c|c|c|c|c|c|c|}
\hline \multirow[b]{2}{*}{ Scenario } & \multirow[b]{2}{*}{ Households } & \multicolumn{6}{|l|}{ Income } \\
\hline & & Lowest quintile & Second quintile & Third quintile & Forth quintile & Highest quintile & Total \\
\hline \multirow[t]{3}{*}{$\overline{\text { Coal }}$} & Expenditure & $\$ 29 K$ & $\$ 46 K$ & $\$ 64 K$ & $\$ 88 \mathrm{~K}$ & $\$ 148 \mathrm{~K}$ & \\
\hline & Counts & 299 & 349 & 224 & 193 & 180 & 1245 \\
\hline & Total expenditure & $\$ 8.7 \mathrm{M}$ & $\$ 15.9 \mathrm{M}$ & $\$ 14.4 \mathrm{M}$ & $\$ 17.0 \mathrm{M}$ & $\$ 26.7 \mathrm{M}$ & $\$ 82.7 \mathrm{M}$ \\
\hline \multirow[t]{3}{*}{ Shutdown } & Expenditure & $\$ 29 \mathrm{~K}$ & $\$ 46 K$ & $\$ 64 K$ & $\$ 88 K$ & $\$ 148 \mathrm{~K}$ & \\
\hline & Counts & 299 & 319 & 204 & 128 & 165 & 1115 \\
\hline & Total expenditure & $\$ 8.7 \mathrm{M}$ & $\$ 14.5 \mathrm{M}$ & $\$ 13.1 \mathrm{M}$ & $\$ 11.3 \mathrm{M}$ & $\$ 24.5 \mathrm{M}$ & $\$ 72.1 \mathrm{M}$ \\
\hline \multirow[t]{3}{*}{ Biomass } & Expenditure & $\$ 29 K$ & $\$ 46 K$ & $\$ 64 \mathrm{~K}$ & $\$ 88 \mathrm{~K}$ & $\$ 148 \mathrm{~K}$ & \\
\hline & Counts & 299 & 394 & 224 & 183 & 180 & 1280 \\
\hline & Total expenditure & $\$ 8.7 \mathrm{M}$ & $\$ 18.0 \mathrm{M}$ & $\$ 14.4 M$ & $\$ 16.2 \mathrm{M}$ & $\$ 26.7 \mathrm{M}$ & $\$ 83.9 \mathrm{M}$ \\
\hline
\end{tabular}

Household expenditure expressed in thousands of dollars $(K=1000)$ and total household expenditure expressed in millions of dollars $(M=1,000,000)$ NOTE: Source file included separately 
Table 2 Induced economic impacts of household expenditure by community under the three power plant scenarios: continuing to burn coal, shutting down the power plant, and conversion of the power plant to biomass

\begin{tabular}{|c|c|c|c|c|c|c|}
\hline \multirow[b]{2}{*}{ Market } & \multirow[b]{2}{*}{ Spatial } & \multirow[b]{2}{*}{ Distance (km) } & \multirow[b]{2}{*}{ Multiplier } & \multicolumn{3}{|c|}{ Scenarios } \\
\hline & & & & Coal & Shutdown & Biomass \\
\hline Atikokan & Locally & 0 & 0.50 & $\$ 41.4 \mathrm{M}$ & $\$ 36.1 \mathrm{M}$ & $\$ 42.0 \mathrm{M}$ \\
\hline Fort Frances & Regionally & 150 & 0.10 & $\$ 8.3 \mathrm{M}$ & $\$ 7.2 \mathrm{M}$ & $\$ 8.4 \mathrm{M}$ \\
\hline Thunder Bay & Regionally & 210 & 0.20 & $\$ 16.5 \mathrm{M}$ & $\$ 14.4 \mathrm{M}$ & $\$ 16.8 \mathrm{M}$ \\
\hline Dryden & Regionally & 210 & 0.05 & $\$ 4.1 \mathrm{M}$ & $\$ 3.6 \mathrm{M}$ & $\$ 4.2 \mathrm{M}$ \\
\hline USA & Out of region & $>210$ & 0.10 & $\$ 8.3 \mathrm{M}$ & $\$ 7.2 \mathrm{M}$ & $\$ 8.4 \mathrm{M}$ \\
\hline \multirow[t]{2}{*}{ Other } & Out of region & $>210$ & 0.05 & $\$ 4.1 \mathrm{M}$ & $\$ 3.6 \mathrm{M}$ & $\$ 4.2 \mathrm{M}$ \\
\hline & & & Est. grand total spending (\$) & $\$ 82.7 \mathrm{M}$ & $\$ 72.1 \mathrm{M}$ & $\$ 83.9 \mathrm{M}$ \\
\hline
\end{tabular}

Regional out-shopping multipliers are based on Knowles [73], with Atikokan capturing $50 \%$ of the market, Fort Frances $10 \%$, Thunder Bay $20 \%$, Dryden 5 \%, USA $10 \%$, and Other $5 \%$

NOTE: Source file included separately

current analysis does not confirm or deny that the effect would be "catastrophic," it does indicate that a shutdown would reduce household incomes leading to less spending in the local economy by $\$ 5.3 \mathrm{M}$ immediately post shutdown. The general observation that small communities, which rely on one or few industries for employment, seldom expand was made in 1971, by Lucas [2]. These communities are "vulnerable to changes in international markets, changes in technology, and in most instances it has a limited life expectancy [2]."

The economic impacts of the shutdown scenario presented in this study are corroborated with similar patterns from other sources. A summary from a European-wide research program indicates that small town economies with a small number of major employers are less resilient and are more adversely affected by economic downturns [75]. A less resilient community is less likely to perform well under stressors such as the loss of a major employer. Furthermore, the community's underling socio-economic profile as defined by Royal Town Planning Institute (RTPI) may also be a contributing factor into its resilience and vulnerability. According to the RTPI, a community's profile can be defined as follows.

- Residential economies emphasize natural and built heritage, amenities, and quality of life.

- Productive economies emphasize specialized skills, knowledge, and practices.

- Knowledge economies emphasize the connectivity to metropolitan areas and attract the creative class and innovative firms [75].

Atikokan's economy which (at the time) centered on the power plant is likely to be primarily a productive economy requiring a specialized workforce. Productive economies become vulnerable when a specialized workforce is no longer required. However, Atikokan possesses characteristics of a residential economy as well. Community members have deep appreciation for Atikokan's residential economy and reported gratefulness to living very close to fishing, hunting, canoeing, and snowmobiling opportunities. Other factors leading to smaller community vulnerability include that they typically receive less government support and have less non-profit organizations, relative to larger centers. Government support and non-profits can help support recovery and transition after a shock [3].

The current model presents the immediate impact of the power plant shutting down as detrimental due reductions in local and regional household spending. In some instances, the loss of a major employer, however, may lead to positive outcomes sometime after the initial shock to the economy and broader community. A case study from rural Lincoln County, Maine, suggests that in the aftermath of a nuclear power plant closure, the community rebounded through reinventing itself [76]. A concerted effort by the local economic development corporation and community stakeholders was made to "diversify the economic base." These revitalization efforts included the development of tourism facilities, local agriculture projects, and a yacht manufacturer. The case study issues a caveat, "Many communities learn the hard way about dependence on a single, major employer. Diversification is essential."

In the biomass scenario, the expanding economy increases overall household counts to 1280, and household expenditures increase by $\$ 1.2 \mathrm{M}$ up to $\$ 83.9 \mathrm{M}$ (Table 1 ). As is the case with the shutdown scenario, the adjustments in household counts were made based on the existing qualitative data from an earlier stage in this project. These data suggest that in order to simulate the biomass scenario, the power plant would likely lose about 10 jobs due to efficiencies introduced in handling biomass relative to coal. Employing the assumption of 10 jobs lost at the power plant, the baseline coal household counts were reduced in the fourth quintile by 10 households (193 households in coal to 183 households 
in biomass). Furthermore, the data also suggest that it is likely that at least 35 wood pellet production jobs would be created in Atikokan, with the wood pellet plants' supply chain being local creating 10 new forestry jobs. Based on these data and assumptions, 45 households in the second quintile were added (349 households in coal to 394 households in biomass) (Table 1).

As Table 2 indicates, the Atikokan local trade area would experience the greatest impact of the biomass scenario leaving $\$ 42.0 \mathrm{M}$ available for Atikokan. Relative to the coal scenario, the increase from $\$ 41.4 \mathrm{M}$ to $\$ 42.0 \mathrm{M}$ in household expenditure for Atikokan represents an increase of $1.4 \%$ for the local economy, which would represent a percent increase keeping in step with inflation. Communities within the region such as Fort Frances, Thunder Bay, and Dryden would also see a small positive effect due to increases in Atikokan household expenditure (Table 2). The increase illustrates that when new businesses are developed from within the community or attracted from outside, an increase in induced economic impact of household expenditure can occur.

Although this study only takes a "snap shot" shortly after the scenarios take effect, it is suggested that the three scenarios would put Atikokan's economy on three divergent trajectories, with differing final consequences: (i) coal would lead to status quo household expenditure, (ii) shutdown would lead to reductions in household expenditure, first by households employed by the power plant and then by households employed by other sectors, and (iii) woody biomass would lead to increases in household expenditure as more people become employed by indirect businesses (related to providing woody biomass to the power plant) and participate in the local economy. Although the presented dollar values are difficult to validate, the model strongly suggests that the three divergent trajectory patterns are valid since the increases and decreases in households represent expanding and contracting economic scenarios adequately. In the future, as SHS and NHS datasets are updated and released by Statistics Canada, they will capture the actual economic changes as the Atikokan economy expands as a result of the woody biomass production and staffing changes at AGS. With the anticipated future data release, the biomass scenario can be validated.

Community leaders viewed woody biomass from local sources as a benefit to the local economy since it supports forest industry activity, which has a long history in Atikokan [27], although some uncertainty exists related to Canadian woody biomass supply chains [77]. A provincially elected official was also quoted in the community newspaper, The Atikokan Progress, supporting the biomass scenario.
Should an alternative fuel source like wood pellets [biomass] be identified as a useable fuel source, potentially we could even source those materials in a community like Atikokan. Besides maintaining the plant, we could potentially see some job creation if we could source the wood pellets, if in fact that became a fuel source [78].

In some instances, increases in economic activity can bring problems, however. Research conducted in resourcedependent communities in Alberta, Canada [79], and Australia [80] suggest that although the economic growth can provide many socio-economic benefits that growth can also produce many unintended negative consequences in boomtown scenarios. Therefore, growth poses a potential risk that could lead to unforeseen problems in the Town of Atikokan. However, the anticipated community growth in the biomass scenario would only result in a net increase of 35 households which would likely be quite manageable for a community of less than 3000 people. Available housing stock could pose a potential challenge though. The community has older, smaller houses. Interview data summarized the potential problem this way, "I think we do have a housing challenge in Atikokan. There's a lot of little housing."

As suggested above in the three scenarios, a neighboring community's proximity to Atikokan influences the extent to which it will be economically impacted; however, distance is not the sole factor. Another factor is neighboring communities' population size. This may help explain why Thunder Bay with a population of over 100,000 and about a $2.5 \mathrm{~h}$ drive away would experience a greater induced economic impact relative to other closer communities. Increased population size suggests more amenities and consumer retail opportunities. Larger amenity-rich communities can draw people for a number of reasons such as providing physiological benefits in the form of entertainment or recreation [81]. Additional factors leading to out-shopping are outlined by Jarratt [82], who presents a concise summary of outshopping behavior. Generalizations include the following: (a) people with increased income and education tend to out-shop more, (b) people with increased age and length of stay in the community tend to out-shop less, and (c) people engaged in out-shopping respond to better prices, variety, and quality in neighboring communities.

These out-shopping generalizations are corroborated with the qualitative findings. One interview participant suggested,

that the workers at OPG [Ontario Power Generation, the power plant] probably are on the higher end of the out-shoppers. Because they can afford to travel, they can afford to go on vacation, they can afford to go for 
entertainment, a $\$ 100$ for a ticket to go to see a show doesn't mean as much to them as to somebody else.

Additionally, an earlier Atikokan study [83] identifies that out-shopping could also be the result of lack of consumer choices.

A primary concern that community leaders have about out-shopping involves seeing dollars which are earned locally "migrate" to other communities, creating negative effects on local small rural communities' economies. Community leaders often recognize the benefits of community members shopping locally and work to curb out-shopping by introducing initiatives such as the $3 / 50$ project [84], which encourages household members to shop locally, supporting mom-and-pop, bricks, and mortar shops.

\section{Conclusions}

This study examined the induced economic impact of three competing outcome scenarios (business as usual-coal scenario, shutdown the power plant-shutdown scenario, convert to renewable woody biomass-biomass scenario) for a small town economy, in response to a provincial-level policy change related to the use of renewable energy. Using provincial-level household expenditure data, local-level household income data, regional shopping behavior data, and local-level expert knowledge and opinion, an induced economic impact assessment model is developed to determine effects of the three scenarios, and induced household expenditures in the local trade area were estimated.

Evaluating the economic impacts of a policy has a number of associated challenges, since evaluation tools have the obvious shortcoming of not allowing the research community to "experiment" on actual economies. However, policy makers can be more effective in their roles, if they better understand and anticipate unintended consequences of their decisions on local and regional economies. When the Ontario government first considered banning coal, the direct, indirect, and induced economic impacts may not have been fully understood by the policy makers, partially due to the previously mentioned dearth of Canadian studies [33]. Therefore, when facing political decisions without adequate knowledge, policy makers should consider using economic assessment tools. These tools can model and help anticipate how alternative decisions may impact communities' economies and help anticipate community response. The three scenarios at the AGS would affect direct and indirect jobs and induced household expenditures. Had decision-makers been able to forecast how the coal ban could impact the economy and the resultant local response, they could have proactively addressed concerns and worries from community members more timely.
A potential weakness with this study is that it does not account for any economic activity related to the transition periods directly associated with shutdown or biomass conversion. Shutdown and decommissioning a power plant or construction during a biomass conversion also provides some short-term, temporary economic benefits within the local trade area through increased household expenditure. In addition to employing the local available workforce, non-local trades people are required to temporarily live and work in Atikokan. Decommissioning would require an input of labor and supplies in order to ensure future environmental or human harm does not occur, while biomass conversion is a major capital upgrade. In either case, it is recognized that these benefits are short-lived and not sustainable after the work is complete. This temporary increase of economic activity benefits businesses operating in the local trade area. These businesses could take the opportunity to invest back into their companies. For example, with an increase in revenue, businesses will be able to address deferred maintenance issues such as upgrading rooms in a motel or updating a refrigeration system in a grocery store.

In order to gain additional insight into direct, indirect, and induced impacts, further study should include using a community-level business survey with a high sampling intensity. However, this approach may be challenging as participants would likely be reluctant to disclose confidential financial data, such as sales, expenses, and profits, or business information such as their client and supplier lists. Furthermore, since this model uses two readily available data sources (SHS and NHS), modelinginduced economic impacts of policy changes in other small Ontario communities can be achieved using the methods presented here.

\section{Abbreviations \\ GDP: gross domestic product; NHS: National Household Survey; ODT: oven-dried tonnes; OPG: Ontario Power Generation; RTPI: Royal Town Planning Institute; SHS: Survey of Household Spending.}

\section{Acknowledgments \\ Financial support from Centre for Research and Innovation in the Bio-Economy (CRIBE) and Ontario Graduate Scholarship (OGS) is highly acknowledged. The authors are also grateful to the leaders of the Town of Atikokan and management of the Atikokan Generating Station for their support and help during this research study.}

\section{Authors' contributions}

All authors have made the substantive intellectual contributions to this study. The lead author under the academic tutelage of the other three authors collaboratively developed (i) the data source collection methods and ii) model development. All authors contributed to the drafting of the final manuscript, and all provided critical revisions and technical input. All authors read and approved the final manuscript.

Competing interests

The authors declare that they have no competing interests. 


\section{Author details}

${ }^{1}$ Faculty of Natural Resources Management, Lakehead University, 955 Oliver Road, Thunder Bay, Ontario P7B 5E1, Canada. ${ }^{2}$ School of Outdoor Recreation Parks and Tourism, Lakehead University, 955 Oliver Road, Thunder Bay, Ontario P7B 5E1, Canada.

Received: 27 September 2015 Accepted: 29 April 2016

Published online: 26 May 2016

\section{References}

1. Randall JE, Ironside RG (1996) Communities on the edge: an economic geography of resource-dependent communities in Canada. Can Geogr 40(1):17-35

2. Lucas RA (1971) Minetown, milltown railtown: life in Canadian communities of single industry. Oxford University Press, Oxford

3. Besser TL (2013) Resilient small rural towns and community shocks. J Rural Community Dev 8(1):117-134

4. Flint CG, Luloff AE (2005) Natural resource-based communities, risk, and disaster: an intersection of theories. Soc Nat Resour 15(5):399-412

5. Wilson-Forsberg S (2013) The adaptation of rural communities to socioeconomic change: theoretical insights from Atlantic Canada. J Rural Community Dev 8(1):160-177

6. Akamani K (2012) A community resilience model for understanding and assessing the sustainability of forest-dependent communities. Hum Ecol Rev 19(2):99-109

7. Markey S, Halseth G, Manson D (2008) Challenging the inevitability of rural decline: advancing the policy of place in northern British Columbia. J Rural Stud 24(4):409-421

8. Reimer B (2005) The rural context of community development in Canada. J Rural Community Dev 1(2):155-175

9. Reimer B (2002) A sample frame for rural Canada: design and evaluation. Reg Stud 36(8):845-859

10. Harris S, Alasia A, Bollman RD (2008) Rural commuting: its relevance to rural and urban labour markets. Rural and Small Town Canada Analysis Bulletin 7(6):1-23, Catalogue no. 21-006-X

11. O'Hagan S, Cecil B (2007) A macro-level approach to examining Canada's primary industry towns in a knowledge economy. J Rural Community Dev 2(2):18-43

12. Halseth G, Ryser $L$ (2006) Trends in service delivery: examples from rural and small town Canada, 1998 to 2005. J Rural Community Dev 1(2):69-60

13. Kures M, Pinkovitz B, Ryan B (2011) Trade area analysis: downtown and business district market analysis. http://fyi.uwex.edu/downtown-marketanalysis/files/2011/02/Trade_Area_Analysis033011.pdf. Accessed 27 Sept 2015

14. Statistics Canada (2012) From urban areas to population centres. http:// www.statcan.gc.ca/subjects-sujets/standard-norme/sgc-cgt/notice-avis/sgccgt-06-eng.htm. Accessed 27 Sept 2015

15. Alasia A, Rothwell N (2003) The rural/urban divide is not changing: income disparities persist. Rural and Small Town Canada Analysis Bulletin 4(4):1-18, Catalogue no. 21-006-XIE

16. Alasia A, Magnusson E (2005) Occupational skill level: the divide between rural and urban Canada. Rural and Small Town Canada Analysis Bulletin 6(2): 1-30, Catalogue no. 21-006-XIE

17. Fortin M (2008) A comparison of rural and urban workers living in lowincome. Rural and Small Town Canada Analysis Bulletin 7(4):18, Catalogue no. 21-006-XIE

18. Rothwell N, Turcotte M (2006) The influence of education on civic engagement: differences across Canada's rural-urban spectrum. Rural and Small Town Canada Analysis Bulletin 7(1):18, Catalogue no. 21-006-XIE

19. Grenier E (2011) Ontario election: divide between rural and urban voters key to Tory loss and liberal minority., Huffington Post Canada, http://www. huffingtonpost.ca/2011/10/07/ontario-election-divide-between-urban-rural_ n_1000146.html. Accessed 27 Sept 2015

20. Corporation CB (2011) Ontario election results create urban-rural split., CBC News, http://www.cbc.ca/news/canada/toronto/ontario-election-resultscreate-urban-rural-split-1.1118405. Accessed 27 Sept 2015

21. Radwanski A (2013) Rural-urban divide makes waves in Ontario race., Globe and Mail, http://www.theglobeandmail.com/news/politics/rural-urbandivide-makes-waves-in-ontario-race/article7080204/. Accessed 27 Sept 2015

22. MacGregor R (2014) As Ontario politicians stump on city issues, rural 'urbanites' feel cut out., Globe and Mail, http://www.theglobeandmail.com/ news/national/media-has-added-to-rural-misdefinition/article18653140/. Accessed 27 Sept 2015

23. Statistics Canada (2011) Census of Canada. http://www.statcan.gc.ca/tablestableaux/sum-som/l01/cst01/demo62g-eng.htm. Accessed 06 July 2014

24. Beshiri $R$ (2010) Manufacturing employment in resource value chains: a rural-urban comparison from 2001 to 2008. Rural and Small Town Canada Analysis Bulletin 8(5):1-34, Catalogue no. 21-006-X

25. Bollman RD (2007) Factors driving Canada's rural economy. 1914 to 2006 agriculture and rural working paper series. Statistics Canada, Ottawa, Catalogue no. 21-601-MIE

26. Rosehart RG (2008) Northwestern Ontario: preparing for change Northwestern Ontario economic facilitator report. Queen's Printer for Ontario, Thunder Bay, ON

27. Dampier JEE, Lemelin RH, Shahi C, Luckai N (2014) Small town identity and history's contribution to a response in policy change: a case study of transition from coal to biomass energy conversion. Energy, Sustainability and Society. doi: 10.1186/s13705-014-0026-4

28. Canadian Chamber of Commerce (2011) Proposed policy resolutions 2011. Canadian Chamber of Commerce, Ottawa, Updated 23.08.11

29. Forest Products Association of Canada (2010) Transforming Canada's forest product's industry. Summary of findings from the future bio-pathways project. Forest Products Association of Canada, Ottawa, ON

30. 30. Ontario (2007) CESSATION OF COAL USE. Ontario regulation 496/07. http://www.ontario.ca/laws/regulation/070496. Accessed 27 Sept 2015

31. Ministry of Energy and Infrastructure (2009) Ontario's coal phase out plan. http://news.ontario.ca/mei/en/2009/09/ontarios-coal-phase-out-plan.html. Accessed 27 Sept 2015

32. Canadian Broadcasting Corporation (2013) Coming of age in a canoe, The National, Broadcast Date: Oct. 21, 2005. http://www.cbc.ca/archives/entry/ coming-of-age-in-a-canoe. Accessed 27 Sept 2015

33. Dampier JEE, Shahi C, Lemelin RH, Luckai N (2013) From coal to wood thermoelectric energy production: a review and discussion of potential socio-economic impacts with implications for Northwestern Ontario, Canada. Energy, Sustainability and Society doi: 10.1186/2192-0567-3-11

34. Marshall L, Fralick C, Gaudry D (2010) OPG charts move from coal to biomass. Power 154(4):30

35. Kryzanowski T (2010) Pellet production boom. Logging and Sawmilling Journal March/April(04/02). http://forestnet.com/LSJissues/march_10/ pellet\%20boom.pdf. Accessed 17 May 2016

36. Ontario (1994) Crown forest sustainability act, S.O. 1994, c. 25. http://www. ontario.ca/laws/statute/94c25/v3. Accessed 29 Sept 2015

37. Kennedy M, Wong R, Vandenbroek A, Lovekin D, Raynolds M (2011) Biomass sustainability analysis. An assessment of Ontario-sourced forest-based biomass for electricity generation. FINAL REPORT. Revision C

38. Generation OP (2011) Atikokan generating station biomass repowering project fact sheet. Ontario Power Generation, Toronto

39. Generation OP (2011) Atikokan generating station brochure. Ontario Power Generation, Inc., Toronto

40. McKinnon M (2011) OPG details the move to biomass. http://www. atikokanprogress.ca/2011/03/23/opg-details-the-move-to-biomass/. Accessed 29 Sept 2015

41. Ontario Power Generation (2012) Atikokan generating station biomass fuel suppliers announced: meeting the needs of a growing economy in Northwestern Ontario. Press Release. http://www.opg.com/news-andmedia/news-releases/Documents/(40)121122Atikokan\%20Fuel\%20Contracts_ FINAL.pdf. Accessed 17 May 2016

42. Alam MB, Pulkki R, Shahi C (2012) Woody biomass availability for bioenergy production using forest depletion spatial data in northwestern Ontario. Can J For Res 42(3):506-516

43. International Energy Agency (2009) World energy outlook 2009. Organisation for Economic Co-operation and Development/International Energy Agency, Paris Cedex, France

44. Olsen P (2010) Atikokan retail and service sector community gap analysis. Edward Hoshizaki Development Consulting, Thunder Bay

45. Statistics Canada (2012) Atikokan, Ontario (Code 0028) and Ontario (Code 35) (table). Census Profile. 2011 Census. Statistics Canada Catalogue no. 98-316-XWE. Ottawa. Released October 24, 2012. http://www5.statcan.gc.ca/olc-cel/olc.action?Objld=98-316-X\&ObjType=2\&lang= en\&limit=0. Accessed 17 May 2016

46. Cox BM, Munn IA (2001) A comparison of two input-output approaches for investigating regional economic impacts of the forest products industry in the Pacific Northwest and the South. Forest Prod J 51(6):39-46 
47. International Energy Agency (2007) Biomass for power generation and CHP. IEA Energy Technology Essentials ETE03. International Energy Agency. https://www.iea.org/publications/freepublications/publication/essentials3. pdf. Accessed 17 May 2016

48. Kebede E, Ojumu G, Adozssi E (2013) Economic impact of wood pellet co-firing in South and West Alabama. Energy Sustain Dev 17(3):252-256

49. Perez-Verdin G, Grebner DL, Munn IA, Sun C, Grado SC (2008) Economic impacts of woody biomass utilization for biomass in Mississippi. Forest Prod J 58(11):75-83

50. Miller RE, Blair PD (2009) Input-output analysis. Foundations and extensions, 2nd edn. Cambridge University Press, New York

51. Baumol W (2000) Leontief's great leap forward. Econ Systems Res 12(2):141-152

52. Polenske KR (1999) Wassily W. Leontief, 1905-99. Econ Systems Res 11(4):341-348

53. Leontief W (1936) Quantitative input-output relations in the economic system of the United States. Rev Econ Stat 18(3):105-125

54. Leontief W (1951) The structure of American economy, 1919-1939: an empirical application of equilibrium analysis, 2nd edn. Oxford University Press, New York

55. IMPLAN Group LLC (2016) IMPLAN system. http://implan.com/. Accessed 17 May 2016

56. Johnson RB (2007) Toward a definition of mixed methods research. J Mix Methods Res 1(2):112

57. Howe KR (1988) Against the quantitative-qualitative incompatibility thesis. Educ Res 17(8):10-16

58. Denscombe M (2008) Communities of practice: a research paradigm for the mixed methods approach. J Mix Methods Res 2(3):270-283

59. Creswell JW (2009) Research design: qualitative, quantitative, and mixed methods approaches, 3rd edn. SAGE Publications, Thousand Oaks

60. Statistics Canada (2015) Table 203-0022-survey of household spending (SHS), household spending, Canada, regions and provinces, by household income quintile, annual (dollars), CANSIM (database). http://www5.statcan. gc.ca/cansim/a26?lang=eng\&id=2030022. Accessed 27 Sept 2015

61. Statistics Canada (2013) National household survey profile. National household survey profile 2011. Ottawa, ON. Catalogue no. 99-004-XWE

62. Creswell JW (2007) Qualitative inquiry \& research design: choosing among five approaches. SAGE Publications, Thousand Oaks

63. Ritchie J, Lewis J, Elam G (2003) Designing and selecting samples. In: Ritchie J, Lewis J (eds) Qualitative research practice: A guide for social science students and researchers. SAGE Publications, London

64. Kvale S, Brinkmann S (2009) InterView: learning the craft of qualitative research interviewing. Sage Publications, Newbury Park

65. DiCicco-Bloom D, Crabtree BF (2006) The qualitative research interview, Med Educ 40(4):314-321

66. Morse JM (1994) Designing funded qualitative research. In: Denzin NK, Lincoln YS (eds) Handbook of Qualitative Research. Sage Publications, Inc, Thousand Oaks

67. Schreier M (2012) Qualitative content analysis in practice. SAGE Publications Inc, Thousand Oaks

68. QSR International Pty Ltd (2012) NVivo qualitative data analysis software Version 10

69. Mayring P (2000) Qualitative content analysis. Forum Qualitative Sozialforschung / Forum: Qualitative Social Research 20. http://www.qualitative-research.net/index php/fqs/article/view/1089/2385. Accessed 17 May 2016

70. Elo S, Kyngas H (2008) The qualitative content analysis process. JAN Res Methodol 62(1):107-115

71. Saldana J (2009) The coding manual for qualitative researchers. Sage Publications, Los Angeles

72. Krippendorff K (2004) Content analysis: an introduction to its methodology. SAGE Publications, Thousand Oaks

73. Knowles G (2013) Community survey executive summary. Atikokan Economic Development Corporation, Atikokan

74. Anonymous (2006) Assessment of the viability of exploiting bio-energy resources accessible to the Atikokan generation station in Northwestern Ontario final report. Forest BioProducts Inc, Ontario Ministry of Energy, Sault Ste. Marie

75. Royal Town Planning Institute (2014) Economic resilience in small and medium sized towns. RTPI research briefing no. 7. Royal Town Planning Institute, London

76. Phillips R (2014) Nuclear plant closes, life goes on: small town resilience in Lincoln County, Maine. Communities and Banking. 25(3):13-14

77. Hughes NM, Shahi C, Pulkki R (2014) A review of the wood pellet value chain, modern value/supply chain management approaches, and value/supply chain models. Journal of Renewable Energy. doi: 10.1155/2014/654158
78. Anonymous (2008) Atikokan generating station tests 100\% wood biomass. Atikokan Progress. http://atikokanprogress.ca/2008/07/28/atikokangenerating-station-tests-100-wood-biomass/. Accessed 27 Sept 2015

79. Parkins JR, Angell AC (2011) Linking social structure, fragmentation, and substance abuse in a resource-based community. Community Work Fam 14(1):39-55

80. Lawrie M, Tonts M, Plummer P (2011) Boomtowns, resource dependence and socio-economic well-being. Australian Geographer 42(2):139-164

81. Burns DJ, Lanasa JM, Lackman CL (1999) Outshopping: an examination from a motivational perspective. J Prof Serv Mark 19(2):151-160

82. Jarratt D (2000) Outshopping behaviour: an explanation of behaviour by shopper segment using structural equation modelling. Int Rev Retail Distrib Consum Res 10(3):287-304

83. Ellis P, Fiddler C, Gill R, Keyworth G, Moretti M, Paske J, Phillips L, Te Z, Vandebelt D, Wright B (2003) Onwards Atikokan: the renewal of an exsingle-industry town. Faculty of Environmental Studies, University of Waterloo, Waterloo

84. Baxter C (2015) The 3/50 project. http://www.the350project.net/home.html. Accessed 27 Sept 2015

\section{Submit your manuscript to a SpringerOpen ${ }^{\circ}$ journal and benefit from:}

- Convenient online submission

- Rigorous peer review

- Immediate publication on acceptance

- Open access: articles freely available online

- High visibility within the field

- Retaining the copyright to your article

Submit your next manuscript at springeropen.com 